\title{
Correspondence
}

\section{Diabetic Coma}

SIR,-We have read Professor R. H. Micks's article (July 24, p. 200) on diabetic coma and there are several points on which we must disagree. It is not true that all America agrees that the giving of glucose early in diabetic coma is dangerous and prevents recovery, a point of view advocated by Dr. Root at Dr. Joslin's Clinic in Boston and supported by Professor Micks. What we are chiefly concerned with, however, is his advice to everyone, practitioners included, to give enormous frequent doses of insulin even in cases of what we call "pre-coma." We shall show that this is unnecessary and must involve the risk of grave hypoglycaemia.

Professor Micks does not give details of a single case to show. how his theory works in practice, but we must quote some of his suggestions without taking them unfairly out of their context. If the patient can give "a clear account of himself " or is only "drowsy and confused " (hardly even precomatose), he should be given 100 units at first, which should produce "an obvious improvement" in 15 minutes. In our experience a subcutaneous injection of insulin never shows any effect in 15 minutes, even in the mildest diabetic. Again, " in an early case, if there is no obvious improvement in half an hour, give 100 units every half-hour until improvement is obvious "-i.e., probably many hundreds of units. We consider this unnecessary and dangerous.

The accompanying table shows four-hourly insulin dosage and blood sugars in three typical severe cases of pre-coma treated during the past year. In each case the patient could only be roused with difficulty and was therefore in a more advanced pre-comatose state than that suggested by Professor Micks's description quoted above. The total amounts of insulin required to remove the ketosis, control the blood sugar, and restore the patient to full consciousness were 124, 142, and 196 units respectively.

\begin{tabular}{|c|c|c|c|c|c|c|}
\hline \multirow{2}{*}{ Hours } & \multicolumn{2}{|c|}{ Case 1} & \multicolumn{2}{|c|}{ Case 2} & \multicolumn{2}{|c|}{ Case 3} \\
\hline & Insulin & Blood Sugar & Insulin & Blood Sugar & Insulin & Blood Sugar \\
\hline $\begin{array}{r}0 \\
4 \\
8 \\
12 \\
16 \\
20 \\
24\end{array}$ & $\begin{array}{l}80 \\
12 \\
12 \\
12 * \\
8 \\
0 \\
-\end{array}$ & $\begin{array}{l}665 \mathrm{mg} . \% \\
256 \text { " } \\
200 \quad " \\
222 \quad " \\
143 \quad " \\
106 \text { _" }\end{array}$ & $\begin{array}{r}60 \\
20 \\
30 \\
24 \\
8 \\
0 \\
0\end{array}$ & $\begin{array}{l}800 \mathrm{mg} . \% \\
572 \% " \\
500=" \\
200-", \\
256 ",\end{array}$ & $\begin{array}{l}40 \\
40 \\
32 \\
40 \\
20 \\
12 \\
12\end{array}$ & 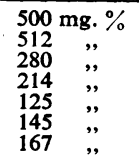 \\
\hline
\end{tabular}

* Ketosis disappearing.

It is obvious that hundreds of units were unnecessary and would probably have produced grave hypoglycaemia-difficult to combat, we find, when vast depots of injected insulin still remain potent. We should add that we have not lost a case of so-called coma of this type for years.

The occasional case, now rarely seen by us, of profound coma with circulatory collapse is quite different, as also is our treatment of it. We give hundreds of units of insulin, but only when we find that the first big dose has had no effect in reducing the blood sugar in 4 hours, taking into account the slight bloodsugar dilution caused by liberal intravenous saline. We press these big doses rather empirically, thinking that owing to circulatory collapse most of this insulin is wasted and ineffective. Occasionally such patients die in spite of enormous doses of insulin and removal of ketosis because of failure to maintain an adequate circulation. This situation is quite different from the mild type mainly described by Professor Micks, where hundreds of units, in our opinion, are both unnecessary and dangerous.-We are, etc.,

Diabetic Department,

King's College Hospital,

London, S.E.5.
R. D. LAWRENCE. WILFRID OAKLEY.

\section{Use and Abuse of Tonsillectomy}

SIR,-It would never do for anyone in authority to implement the opinion expressed by Dr. H. Stanley Banks at the Preventive Medicine Section of the Annual Meeting of the British Medical Association (July 17, p. 161) that the prohibition of tonsillectomy during epidemics (of poliomyelitis) is the only useful administrative measure of control (against the disease). But Dr. Banks's pronouncement is an important and a valuable one. Here is a well-known physician, a leader in his branch of medicine, who wants temporarily to stop all removal of tonsils during a time when some disease is prevalent that seems to him of greater importance. His opinion sounds like a challenge to Mr. V. E. Negus, speaking in another section on the same subject, to produce his evidence of the "various troubles caused by not doing the operation" until the epidemic is passed.

Let us see where such an order might lead us to. Poliomyelitis is not the only disease to which it might be applied. The post-tonsillectomy measles mastoid is so deadly that to take out tonsils during an epidemic of measles from a child who has not had the disease is as risky as to do so during an epidemic of poliomyelitis. Then were such an order made I should demand that it be extended to all such operations during the winter months and should have behind me the support of many leading physicians. I have applied the principle of cessation of tonsil operations during winter months and during measles epidemics for twenty years and have never seen any "trouble" arising from the delay. But if temporary cessations, seasonal and epidemiological, of tonsillectomy are much to be desired, why should not the administrative fiat be extended to the whole holocaust of tonsils that has been going on for a quarter of a century? It might be ordered that none should be removed under the age of nine, and then only for indications that could not be exceeded. No! Salutary as such orders would be in many ways, we cannot conduct the art of medicine by administrative fiats, and this part of the art must be amended by two other methods.

The first is that the profession as a whole should reconsider its approach to tonsillectomy. Practically every experienced physician in the land deprecates its excessive frequency. The Ministry of Education has, short of dictation, done all it can to limit the number arising from its school inspections. Yet still it goes on to such an extent that it can only be explained as being due to a disharmony of the human mind. Future generations will, I believe, wonder, and some may laugh, at our propensity to it, just as we do at the bleeding and purging of the end of the eighteenth and beginning of the last century.

The other is that parents should again assume the responsibility for decision that they have so long laid aside. The doctor does not order, he advises. If parents would say, "No, I will not have my child operated on until the epidemic is over (or until the winter is past)," they would find that the child is none the worse for the delay, and often that it has entirely recovered from the symptoms for which the operation was originally advised. The reassumption of their responsibility might thus lead inquiring minds to demand more from the doctors who advise this operation than they have in the past, and this in its turn might ensure the profession as a whole making that reconsideration that seems so necessary.-I am, etc..

London, W.1.

T. B. LAYTON.

\section{Renal Complications in Diabetes Mellitus}

SIR,-We would like to make a comment on the interesting article on renal complications in diabetes mellitus by Drs. W. R. Gauld, A. L. Stalker, and A. Lyall (July 24, p. 194). The authors admit, and we agree, that there is no certain way of distinguishing during life between intercapillary glomerulosclerosis and subacute nephritis (we should prefer to say Type II nephritis). Having found one case (No. 13) in which the typical lesions of Kimmelstiel and Wilson were not found at necropsy, they create a new group of three cases of "subacute nephritis" complicating diabetes, although in the other two cases there has been no necropsy evidence. The only criterion used by the authors in putting the other cases into. this group seems to be the age of the patients. 